\title{
Practical Aspects in the Evaluation of Infectious Esophagitis
}

\author{
M. Kriegsmann ${ }^{1,2 *}$, N. Arens ${ }^{2}$, M. Otto ${ }^{2,3}$ and J. Kriegsmann ${ }^{2,3}$ \\ ${ }^{1}$ Institute of Pathology Heidelberg, Germany \\ ${ }^{2}$ Molecular Pathology Trier, Germany \\ ${ }^{3}$ Center for Histology, Cytology and molecular Diagnostics Trier, Germany
}

\begin{abstract}
Infectious esophagitis is a common complication in immune compromised hosts and associated with a high morbidity. When faced with esophagitis one should be aware of simultaneous infection by different agents. In this paper we present practical aspects and introduce the different methods used in routine evaluation of esophageal specimens.
\end{abstract}

Keywords: Esophagus; Esophagitis; Herpesvirus; Candida; Molecular pathology.

\section{Introduction}

Infectious Esophagitis is a rare disease in healthy individuals. In immune compromised patients it is a common complication and associated with a high morbidity $[1,2]$. At special risk are patients with human immunodeficiency virus (HIV) infection or leucopenia, recipients of transplants or patients on immunosuppressive medication $[1,3]$. Esophageal infection may be caused by fungi, bacteria or viruses. Candida is the most common agent, followed by Streptococcus, Staphylococcus, Herpes simplex virus (HSV), Cytomegalovirus (CMV), Epstein-barr virus (EBV) and HIV. Occasionally, Aspergillus spec., Varicella zoster virus (VZV), Mycobacteria sps. or Actinomyces sps. are detected [1-5]. Frequently, there is evidence of several pathogens but simultaneous infection by different viruses is rare [6,7].

Patients with esophagitis usually present with dysphagia and odynophagia. Furthermore, retrosternal pain and fever are observed $[1,8]$. Blood tests may help to confirm general infection. However, serological studies for specific herpesviruses don't add in the diagnostic evaluation due to the high prevalence in the healthy population. Thus, for further evaluation an esophago-gastro-duodenoscopy (EGD) with subsequent biopsies is generally performed.

For histo pathological investigation of esophageal biopsies, hematoxylin and eosin (H\&E) staining, histo chemical, immune histochemical and molecular biological methods are available. A combination of these techniques is usually used in routine diagnostics since especially in immune compromised hosts, simultaneous infections may occur.

\section{Sequential Evaluation in Patients with Esophagitis}

\section{Endoscopy}

An EGD may show clues toward a specific infection. The aspect and the location of the lesions may be different in various agents. Whereas white plaques that may be localized or diffuse are characteristic of Candida infection[8], ulcerations may point toward malignancies or herpes-virus infections. HSV and CMV predominantly affect the distal esophagus but the entire length may be involved[7]. EBV infection is often localized in the proximal and mid parts of the esophagus [3]. For the detection of HSV, biopsies should be taken from the edge of an ulcerated lesion. In contrast, CMV and EBV are better detected from the center of the ulcer base [3,5,9]. Since different viruses show variability concerning their best traceability, sampling should include three or more specimens at different locations during EGD to be considered appropriate $[7,10]$.

\section{Histology}

Biopsy specimens taken during EGD are immediately transferred to a formalin solution, dehydrogenized in graded alcohol and embedded in paraffin (FFPE). Paraffin blocks are cut with a microtome and approximately $8 \mu \mathrm{m}$ thick tissue sections are mounted on a glass slide. Routine histological sections stained with H\&E (Figure. 1) allow the diagnosis of esophageal infections in many cases, while double infections are very difficult to detect.

Viruses may infect different cell types and histology is variable. However, some have characteristic features that may, but not always, be present. Viral infections often cause defects of the squamous

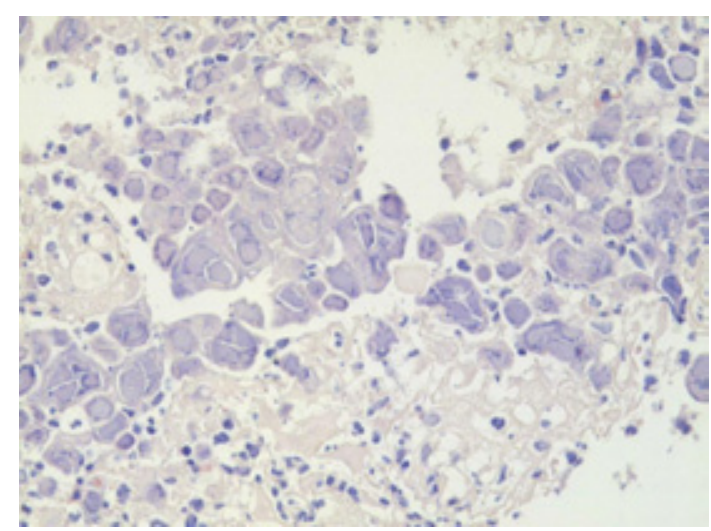

Figure 1a: Epithelial cells with typical ballooning (arrow), and groundglass or inclusions, scattered Lymphocytes (arrowhead) are also present (H\&E,20x).

*Corresponding author: Mark Kriegsmann, University of Heidelberg, Im Neuenheimer Feld 22469120 Heidelberg, Germany, Tel: +49 (0)6221 56 36930; E-mail: mark.kriegsmann@med.uni-heidelberg.de

Received May 25, 2013; Accepted June 13, 2013; Published June 17, 2013

Citation: Kriegsmann M, Arens N, Otto M, Kriegsmann J (2013) Practical Aspects in the Evaluation of Infectious Esophagitis. Clin Microbial 2: 119. doi:10.4172/23275073.1000119

Copyright: (C) 2013 Kriegsmann M, et al. This is an open-access article distributed under the terms of the Creative Commons Attribution License, which permits unrestricted use, distribution, and reproduction in any medium, provided the original author and source are credited. 
Citation: Kriegsmann M, Arens N, Otto M, Kriegsmann J (2013) Practical Aspects in the Evaluation of Infectious Esophagitis. Clin Microbial 2: 119. doi:10.4172/2327-5073.1000119

Page 2 of 3

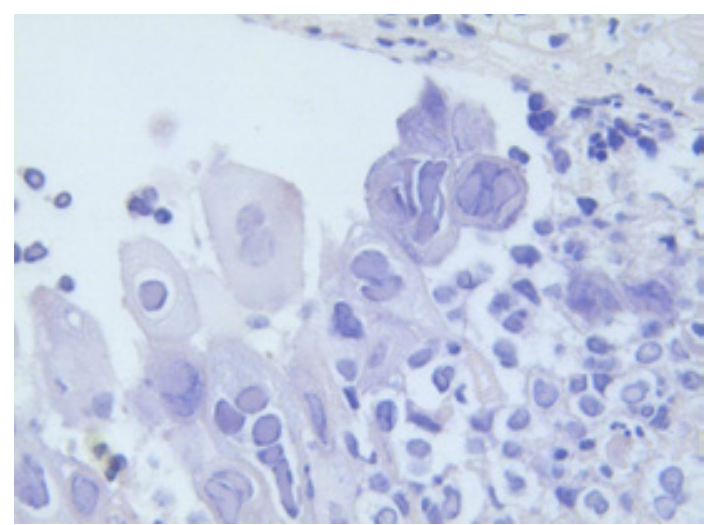

Figure 1b: Close view of epithelial cells with multiple HSV inclusions and multinucleated cells with morphological signs of viral infection (40x).

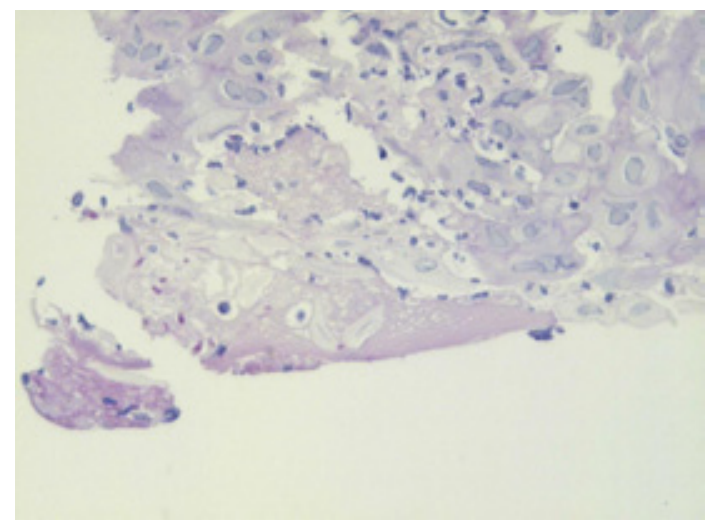

Figure 2: PAS-stain shows PAS-positive fungal structures consistent with Candida infection (arrow) and additional HSV infected cells (arrowhead) (PAS, 20x).

epithelium (erosions or ulcers). Typical ground glass cells or multinucleated giant epithelial cells are a hallmark of HSV infections (Figure 1). Homogenized nuclear chromatin, multinucleation with molding of nuclei and ballooning of cells are the main features (Figure 1b). Sometimes Cowdry A or B inclusion bodies are present.

CMV infects endothelial, stromal, and epithelial cells. Characteristic are cells with eosinophil intranuclear inclusions ("owl's eye"), a peripheral halo and prominent chromatin. Often there are associated multinucleated giant cells $[9,10]$. Whether EBV infection is a distinct disease entity or an "innocent bystander" remains controversial. Diagnosis of different viruses in esophagitis by histology alone is challenging and should be proven by immunohistochemistry or molecular techniques that allow detection with high sensitivity and specificity [7].

\section{Histochemistry and molecular methods}

Histochemistry has been proven to provide additional information in many cases and includePeriodic acid-Schiff(PAS) and Grocott's reaction for the detection of Candida spores/pseudohyphes (Figure 2) or other fungi and Giemsa stain to evaluate eosinophilic esophagitis. When histochemistry shows arbitrary results, or if there is uncertainty on the fungal subtype, PCR with subsequent chip technology or sequencing are suitable methods for routine use [11].
Immuno histochemistry for the detection of infectious agents includes antibodies against HSV (Figure 3 ) and CMV. For simultaneous detection of HSV1/2 (HHV1/2) EBV (HHV4),CMV (HHV5), HHV6 and VZV (HHV3) we currently use a multiplex PCR using 5 nested primer pairs (20 primers in total) as described previously [12]. A positive result is indicated by a specific size of PCR fragments: $120 \mathrm{bp}$ (HSV1/2), 98 bp (VZV), 78 bp (CMV), 66 bp (HHV6), and 54 bp (EBV) (Figure 4). In routine diagnostics, PCR methods that are conducted on tissue specimens are well established $[1,9]$ and superior to virus culture [9]. We have seen cases with double infection of fungi and HSV (Figure 2) as well as with HSV and CMV or CMV and EBV (Figure 4).

\section{Conclusion}

Infectious esophagitis may present with a variety of clinical signs and a biopsy should generally be performed to rule out a malignant process or a double infection. The differential diagnosis between esophageal erosions or ulcers caused by a malignant process or by pathogens may be challenging not only for the clinician but also for the pathologist. The main clinical condition for the occurrence of esophageal infection is breakdown of the immune system. Especially in this condition, biopsy specimens should undergo careful histological examination for morphological signs of fungal or viral infections. Viral infections are characterized by ballooning of epithelial cells, cellular inclusions and chronic or acute inflammatory infiltrates. However, histomorphological changes are generally non-specific and one should bear in mind that infection by one agent may increase cellular vulnerability to other infections. Thus, special histo chemical and immune histo chemical methods are required to ensure the diagnosis. Molecular techniques which can be applied on FFPE-tissue include PCR followed by

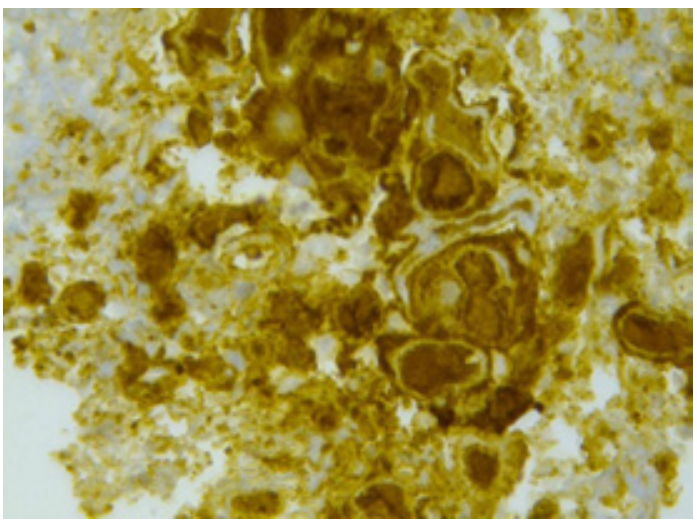

Figure 3: Immunohistochemical investigation of an esophageal biopsy with antibodies against HSV. Strong staining in the nucleus and to a lesser extend in the cytoplasm of squamous epithelia (40x).

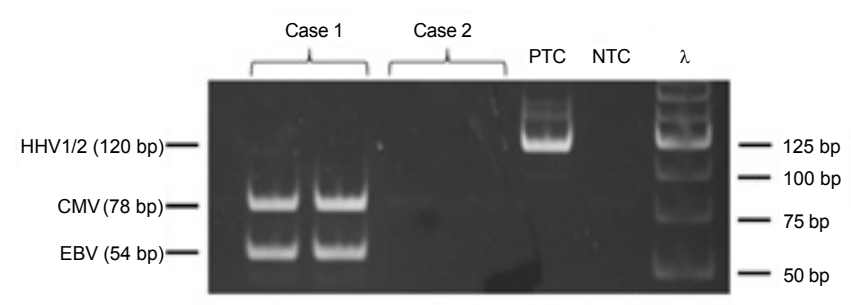

Figure 4: Herpes virus specific PCR shows positivity for CMV and EBV but not for HHV1/2 in Case 1, whereas in Case 2 no Herpes virus infection could be identified. 
Citation: Kriegsmann M, Arens N, Otto M, Kriegsmann J (2013) Practical Aspects in the Evaluation of Infectious Esophagitis. Clin Microbial 2: 119. doi:10.4172/2327-5073.1000119

Page 3 of 3

sequencing or by chip technologies, where hybridization of the PCRproduct and hybridization to viral or fungal DNA-sequences allow exact classification of the causative infectious agent. The detection of the causative agents is essential, since therapy differs substantially and serious complications as bleeding and perforation should be avoided by adequate treatment [4].

\section{References}

1. Baehr PH, McDonald GB (1994) Esophageal infections: risk factors, presentation, diagnosis, and treatment. Gastroenterology 106: 509-532.

2. Thom K, Forrest $\mathrm{G}$ (2006) Gastrointestinal infections in immunocompromised hosts. Curr Opin Gastroenterol 22: 18-23.

3. Pape M, Mandraveli K, Sidiropoulos I, Koliouskas D, Alexiou-Daniel S, et al. (2009) Unusual Epstein-Barr esophageal infection in an immunocompetent patient: a case report. J Med Case Rep 3: 7314.

4. Canalejo Castrillero E, García Durán F, Cabello N, García Martínez J (2010) Herpes esophagitis in healthy adults and adolescents: report of 3 cases and review of the literature. Medicine (Baltimore) 89: 204-210

5. Bobak DA (2003) Gastrointestinal Infections Caused by Cytomegalovirus. Curr Infect Dis Rep 5: 101-107.
6. Vodovnik A, Cerar A (2000) Synchronous herpes simplex virus and cytomegalovirus esophagitis. Z Gastroenterol 38: 491-494.

7. Albuquerque A, Cardoso H, Ribeiro A, Rios E, Silva R, et al. (2012) Herpes and cytomegalovirus esophagitis. Endoscopy 44 Suppl 2 UCTN: E242-E243.

8. Maragkoudakis E, Realdi G, Dore MP (2005) [Fungal infections of the gastrointestinal tract]. Recenti Prog Med 96: 311-317.

9. Itoh T, Takahashi T, Kusaka K, Kawaura K, Nakagawa Y, et al. (2003) Herpes simplex esophagitis from 1307 autopsy cases. J Gastroenterol Hepatol 18: 1407-1411.

10. Srilatha PS, Suvarna N, Gupta A, Bhat G (2011) Esophageal ulcer in a HIVseropositive patient co-infected by herpes simplex and cytomegalovirus. Indian J Pathol Microbiol 54: 219-220.

11. Vernet G (2002) DNA-chip technology and infectious diseases. Virus Res 82 65-71.

12. Tenorio A, Echevarría JE, Casas I, Echevarría JM, Tabarés E (1993) Detection and typing of human herpesviruses by multiplex polymerase chain reaction. $J$ Virol Methods 44: 261-269. 